\title{
Tecnologia, Políticas e Inclusão Social: uma Entrevista com Susan Cozzens
}

Technology, Policies and Social Inclusion: an Interview with Susan Cozzens

\author{
Susan Cozzens (Entrevistada) \\ Rafael Bennertz (Entrevistador) \\ Maiko Rafael Spiess (Entrevistador) \\ Rafael de Brito Dias (Entrevistador)
}

\section{Resumo}

Nesta entrevista, Susan Cozzens comenta algumas das peculiaridades de sua formação e atuação como policymaker na National Science Foundation e posteriormente como pesquisadora de Políticas de Ciência, Tecnologia e Inovação (C,T\&l). Ela oferece um relato pessoal e reflexivo sobre como foi ingressar no campo dos Estudos Sociais da Ciência, sob orientação de Robert K. Merton (1910 2003) no início dos anos 1980 , sobre como era o contexto de emergência do campo e quais eram as dificuldades iniciais encontradas pelos pesquisadores desta área durante a sua institucionalização nos EUA. Além do relato pessoal, Susan provoca uma reflexão sobre como pode ser possível uma reorientação das políticas de C,T\&I visando a melhoria da qualidade de vida das populações empobrecidas. A entrevista contribui, portanto, para uma melhor compreensão sobre a história do campo de estudos de C,T\&I nos EUA e também instiga à análise crítica do papel da C,T\&I nas sociedades contemporâneas e para os países em desenvolvimento.

Palavras-chave: Susan Cozzens; Ciência, Tecnologia e Inovação; Sociologia da Ciência; Estudos de Políticas de Ciência, Tecnologia e Inovação; Estudos Sociais da Ciência e da Tecnologia.

\begin{abstract}
In this interview Susan Cozzens talks about some peculiarities about her training and work as a policymaker for the National Science Foundation, and as a Science, Technology and Innovation (ST\&l) researcher. She offers a personal and reflexive account on joining the Social Studies of Science (SSS) field under the supervising of Robert K. Merton (1910 - 2003) in the early 1980s, the emergence of this field, and the main difficulties the area researchers faced during its institutionalization in the US. Besides that, Susan provides a reflection on the possible reorientation of ST\&I policies towards an improvement of poor population's living standards. This interview helps to achieve a better apprehension of the field's history in the US, and incites the critical evaluation of the ST\&I in contemporary societies and in the developing countries.
\end{abstract}

Keywords: Susan Cozzens; Science, Technology and Innovation; Sociology of Science; Science, Technology and Innovation Policy Studies; Social Studies of Science and Technology.

\section{Introdução}

Susan Cozzens faz parte de um pequeno grupo de pessoas que teve a oportunidade de participar da constituição e da consolidação do campo disciplinar dos Estudos Sociais da Ciência e da Tecnologia (ESCT). O seu ingresso neste campo em emergência se deu por meio da Sociologia da Ciência na Universidade de Columbia, onde Robert King Merton (1910-2003), um dos principais representantes da Sociologia da Ciência nos Estados Unidos, era professor.

Como estudante em Columbia, Susan presenciou o surgimento da Sociedade para Estudos Sociais da Ciência (Society for Social Studies of Science - 4S) e entrou em contato com trabalhos de pioneiros da bibliometria e da cienciometria. Mais tarde, ela entrou para o mundo das Políticas Públicas de Ciência, Tecnologia e Inovação (C,T\&l), trabalhou no Institute for Scientific Information (ISI) e na National Science Foundation (NSF). Nesta entrevista, Susan reflete também como a sua formação em sociologia da ciência a permitiu compreender melhor e atuar de forma mais qualificada no mundo das Políticas Públicas de C,T\&l, e por outro lado, aponta como essa experiência proporcionou uma compreensão mais refinada sobre o funcionamento e a organização da 
comunidade científica.

Após defender a sua tese, passou a atuar principalmente como pesquisadora acadêmica, no entanto seu histórico de vida profissional influenciou fortemente as suas pesquisas. A atuação no mundo da Política a instigou a refletir mais sistematicamente acerca do papel da C,T\&I para o desenvolvimento. A preocupação em orientar a pesquisa e o desenvolvimento (P\&D) para a solução de problemas socioeconômicos evidencia-se em seus temas de pesquisa, que abrangem políticas de C,T\&I em países em desenvolvimento, nanotecnologia, desenvolvimento de métodos de avaliação e indicadores de C,T\&l, empreendedorismo social, tecnologias emergentes, programas tecnológicos para os pobres, entre outros que buscam refletir sobre questões de justiça, igualdade e desenvolvimento.

Atualmente, Susan Cozzens tem sido chamada a dar consultoria para órgãos de pesquisa e proferir palestras em diversos países, e também contribuiu como editora de importantes revistas da área como Science, Technology and Human Values, Science and Public Policy e Research Evaluation. Em março de 2010, para participar de diversas palestras ${ }^{1}$, Susan esteve no Brasil e nesta ocasião tivemos a oportunidade de entrevistá-la para assim apresentá-la ao público brasileiro mais amplo.

\section{Entrevista}

Entrevistador: Você foi orientada por um dos mais famosos sociólogos da Ciência, Robert K. Merton. Antes de passarmos para seus interesses de pesquisa mais recentes, gostaríamos de falar um pouco sobre sua carreira. Como ela começou? Se você pudesse resumir essa fase inicial da sua carreira, quais seriam os pontos altos? Além disso, nós estamos interessados em saber sobre o início do campo dos Estudos Sociais da Ciência. Como era ser um estudante de Sociologia da Ciência nos anos 1970? Qual o relato que você poderia nos dar sobre o campo naquele tempo?

Susan Cozzens: Quando eu fui para a pós-graduação em Columbia, na realidade, eu estava interessada na Sociologia do Conhecimento, em como as pessoas se comunicavam através de barreiras culturais e, particularmente, de onde vem as estruturas de conhecimento e como elas se conectam à sociedade. Então, eu fiz uma disciplina nessa área com Bernard Barber, que escreveu o livro Ciência e a Ordem Social ${ }^{2}$, que me proporcionou uma introdução à área. Uma vez que você se interessava por essa área em Columbia naquele momento, porque Merton estava lá, e porque os trabalhos em Sociologia da Ciência eram muito fortes, você era encorajado a se direcionar para a Sociologia da Ciência. E foi assim que eu acabei ali - não por causa de uma fascinação inicial com a ciência em si, mas pelo interesse no Conhecimento.

Então eu trabalhei com outros estudantes e com Merton em Columbia, aprendendo esse campo. Era uma época empolgante para os Estudos Sociais da Ciência. Enquanto eu estava na pósgraduação, a primeira reunião da Society for Social Studies of Science (ou apenas 4S) aconteceu em Cornell, em 1976 - eu perdi essa porque eu estava me casando (o que era uma boa desculpa). Naquele tempo a interação interdisciplinar era muito animadora. História, Filosofia e Sociologia estavam se unindo. A mistura disciplinar se ampliou mais tarde, mas havia muita História, Filosofia e Sociologia juntas e, naquele momento, Merton estava realmente entusiasmado com isso - ele realmente amava aprender a respeito dessas áreas. Ele era um acadêmico dedicado, sempre empolgado em ouvir os outros. Ele sempre pensava teoricamente sobre qualquer situação que ele observava. Por isso, era interessante estar ali. Eu tinha uma bolsa de estudos quando eu comecei em Columbia, e não me apressei em terminar meus créditos. Eu fiz os exames e então a bolsa acabou, eu tive que arrumar um ganha-pão. Naquele tempo, eu estava morando na Filadélfia, que era onde o meu marido vivia e então eu estava indo e voltando de Nova lorque para a Filadélfia. Eu comecei a procurar um trabalho.

Uma das coisas que estavam acontecendo naquele tempo no nosso campo era que havia uma área chamada Specialty Studies, que eram estudos sobre áreas específicas na ciência. Alguns dos líderes dessa área estavam usando literature based data, incluindo agrupamento de co-citações e, na verdade, eles estavam na Filadélfia. O pessoal de Columbia me deu uma introdução ao pensamento de Henry Small ${ }^{3}$ no Institute for Scientific Information (ISI) ${ }^{4}$, e eu acabei conseguindo um emprego lá, trabalhando com dados de citações com aquele grupo por quatro anos. Isso também era muito excitante, enquanto uma parte da história do campo. Naquele ponto, Henry havia inventado uma técnica para encontrar Specialty Areas e rastreamento de mudanças na ciência, com Belver Griffith, que também estava na Filadélfia. Derek Price ${ }^{5}$ aparecia de tempos em tempos, e dava pequenos seminários, principalmente para os estudantes de Ciências da Informação que estavam trabalhando com Henry e Belver; foi assim que eu corri para ouvi-lo. Era um lugar muito animador para estar, intelectualmente também. Nós fazíamos pesquisas encomendadas que usavam a base de 
dados de citações, para estudos específicos para pessoas que os encomendavam. Foi assim que eu fui parar no mundo da Política, porque alguns dos trabalhos eram para clientes do setor público.

Nesse caminho, uma das áreas na qual estávamos trabalhando com dados de citação era a descoberta dos receptores opiáceos; isso se tornou minha tese. Eu estava fascinada com a ideia dos neurotransmissores - as moléculas químicas que se encaixam em uma célula nervosa e enviam sinais celulares fazendo com que essas células executem o que eles [os neurotransmissores] querem que elas façam. Eu acabei escrevendo minha tese sobre esse tema. Foi uma combinação de entrevistas e alguns dados da literatura que procurou mostrar como a controvérsia social envolvendo isso foi encerrada.

Enquanto eu estava no ISI eu recebi um anúncio de uma vaga na National Science Foundation (NSF). Eu fiz a entrevista para ela e consegui o emprego. Eu fui entrevistada numa segunda-feira, e uma das perguntas era "o quão rápido você pode começar, se conseguir o trabalho?" - e as pessoas sempre nos dão esse conselho, "quando você vai para entrevistas de emprego você sempre deve parecer empolgado e estar pronto para ele" - e eu disse 'assim que vocês precisarem de mim', então eles me telefonaram na terça e disseram "estamos lhe oferecendo o trabalho; você pode começar na próxima segunda?". Foi assim que eu fui para Washington. Eu deixei meu marido na Filadélfia com um emprego, e nós tínhamos uma pequenina: minha filha tinha talvez 18 meses, ou talvez um pouco menos. Por isso, aquela foi uma grande decisão para nós, como uma família. Mas eu realmente queria o emprego, então meu marido tomou a iniciativa e disse "OK, nós faremos isso, vamos dar um jeito de lidar com isso". Então eu fiz minha transição para a NSF fazendo análise de políticas.

Para resumir, um ponto crítico da minha carreira foi ir para Washington e estar imersa na NSF, que é uma organização central. Ela não é a maior organização científica nos Estados Unidos, mas está conectada a diferentes comunidades disciplinares. Nós estávamos fazendo análises para os tomadores de decisões e para o Office of Management of Budget, sobre o que estava acontecendo na comunidade científica, sobre como o financiamento estava afetando a ciência de diversas maneiras. Todas as ferramentas que eu aprendi na Sociologia da Ciência foram muito úteis no mundo da política. De certo modo, eu fui mordida pelo bichinho da política. Eu estava fascinada pela dinâmica da comunidade. Eu estava fascinada pelos seus aspectos políticos porque a visão da escola mertoniana é apenas sobre a comunidade científica em si, ela quase não menciona o fato de que estas pessoas estariam provavelmente localizadas na Universidade, eles apenas milagrosamente querem publicar e conseguir reconhecimento pelo que publicam. Não havia noção sobre a esfera política e como ela poderia afetar o modo como o campo era moldado. Isso tudo era um território novo, e para uma estudante de Merton isso era realmente fascinante. Eu fiquei realmente interessada pelo poder, e pela relação entre poder, autonomia e produção do conhecimento porque havia trabalhado na NSF.

Ao final deste período eu estava trabalhando na minha tese (infelizmente, porque trabalhar nestes dois empregos realmente pode atrasá-lo; eu não recomendo isso à ninguém). Quando eu finalmente terminei a redação da tese e entrei para o mercado de trabalho acadêmico eu comecei a me tornar uma pesquisadora universitária, ao invés de uma pesquisadora do governo.

Entrevistador: Corrija-me se estiver errado, mas é possível afirmar que a sua dissertação, seu livro é influenciado pelo referencial de Merton. No entanto, desde o final dos anos 1970 e começo dos anos 1980 esses tipos de estudo foram, de alguma maneira, negligenciados e os pesquisadores pareceram também mais preocupados com estudos de caso construtivistas (ainda que o seu livro seja também baseado em um estudo de caso específicos). Eu estou falando aqui das análises da ciência de cunho construtivista e de nível micro. De todo modo, Karin Knorr-Cetina, em seu artigo sobre as arenas trans-epistêmicas ${ }^{6}$, afirma que as comunidades científicas são algo como um construto sociológico elaboradas pelos sociólogos, com pouca semelhança com a realidade que eles tentam explicar, algo que parece estar "nos olhos de quem vê". Em sua opinião, isso está correto? O que você pensa sobre esse tipo de crítica e, além disso, o que permanece sendo importante nessas análises normativas e internalistas da Ciência, tipicamente mertonianas? Elas permanecem relevantes?

Susan: Essa é uma boa questão, uma questão muito provocativa. Trabalhando com o mundo da política você encontra muitas ideias ingênuas sobre estrutura na ciência. De fato, as pessoas usam a palavra "campo" ou também "disciplina" como se elas fossem completamente não-problemáticas essas duas palavras provavelmente mais do que comunidade. Trabalhando com dados quantitativos (o que eu fiz por muito tempo), várias vezes encontram-se dados utilizados de maneira ingênua, nas quais alguém os manipula e estrutura alguma justificativa para a manipulação, e então atribuem realidade àquela estrutura. Muito disto está acontecendo agora mesmo!

Uma das coisas que eu trouxe da Sociologia da Ciência e da Política é a noção de quão ingênuos aqueles vocabulários e aquelas construções, a partir dos dados quantitativos, são. Ainda que eu estivesse estudado em Columbia com Merton, eu estava ao mesmo tempo absorvendo as 
ideias sobre o Construtivismo Social. Basicamente, eu sou simultaneamente uma estudante de Merton e uma construtivista social em termos de como eu penso sobre as comunidades de pesquisa, sobre as redes de pesquisa e as interações de pesquisa e como elas se somam. Eu penso que estes antecedentes na verdade me deram mais densidade para manter minha posição e providenciar uma crítica dos conceitos de redes na Política. Eu acho que isso é o argumento central daquilo que KnorrCetina está falando nesse artigo, não reificar a "comunidade científica", mas aprimorando a compreensão da maneira como o conhecimento é realmente construído pelos atores naquela área. Eu creio que isso é perfeitamente válido e razoável para que isso seja mais amplamente compreendido na Sociologia da Comunidade Científica.

Dito isso, até onde eu sei, os aspectos estruturais e o tipo de ideias centrais da teoria mertoniana do sistema de recompensas na ciência, vão fundamentar diretamente os círculos de credibilidade de Latour e Woolgar . Excetuando-se o vocabulário e a maneira como isso é descrito, não há muita diferença. Essas ideias foram, recentemente, adotadas também por economistas, em seu entendimento sobre como a pesquisa está operando em certos sistemas de recompensas e como eles estão constituindo o que eu chamaria de um "modelo da comunidade de pesquisa baseado no agente", que é a mais recente moda na modelagem de dados quantitativos. Isso está recebendo atenção na política.

Todas essas coisas têm vocabulários distintos, mas as idéias e as noções fundamentais sobre o que faz um cientista pensar e fazer o que ele ou ela fazem estavam todas ali em Merton. Eu acho que está havendo uma redescoberta de Merton, e eu nunca vi o modelo mertoniano como incompatível com a visão do construtivismo social sobre o que as estruturas sociais são ou sobre como as pessoas operam e como o conhecimento é construído.

Entrevistador: O quanto é difícil ter uma formação forte no Construtivismo Social e também trabalhar na elaboração de Políticas Públicas? Parece que, de certa maneira, você teve que abrir mão de certos pressupostos quando pensando sobre políticas e propondo coisas.

Susan: Eu acho que trabalhar com Políticas Públicas, trabalhar no mundo da política, e continuando no mundo dos estudos sobre políticas públicas me fizeram deixar muito do vocabulário para trás, porque você realmente não consegue falar como um pesquisador dos Estudos Sociais da Ciência e da Tecnologia (ESCT) e continuar se comunicando com os policymakers e suas equipes. Mas você ainda pode pensar como um pesquisador dos ESCT. Você pode questionar a reificação das estruturas e as bases teóricas das medidas adotadas. Você pode levar as dinâmicas públicas mais amplas em consideração. Algumas vezes, é difícil para analistas de políticas públicas, que não tiveram que pensar sistematicamente sobre a prática científica, fazerem isso.

Entrevistador: Em seu artigo "Science, Government and the Politics of Knowledge" (1995) ${ }^{8}$, você destaca que os ESCT estão baseados principalmente na existência de "ação" - como no Construtivismo Social, nos Estudos de Controvérsias ou nos Governamentally Oriented Studies naquilo que está "acontecendo". Mas o artigo também chama a atenção para o fato de que pode ser mais esclarecedor analisar "Assuntos que não emergem para a discussão pública porque alguma situação, seja estrutural ou uma força cultural, suprime a discordância latente"'. Essa proposta soa muito desafiadora. Você poderia falar mais sobre ela e explicar seu ponto de vista? Isso pode ser relacionado com a importância dos ESCT para as políticas públicas?

Susan: O discurso convencional da Política de Ciência e Tecnologia nos Estudos Unidos incorpora certos silêncios polidos. O maior exemplo disso é a falta de atenção para a pesquisa e desenvolvimento militares e seu papel no direcionamento da atenção da ciência e engenharia para soluções dos problemas militares, ao invés dos problemas humanos ou ambientais. Outro quase silêncio é a falta de questionamento se as pessoas que estão na base da escala de renda estão se beneficiando da agenda de pesquisa. A razão para este silêncio é muito clara: nenhum desses tópicos é politicamente popular nos EUA, então a política de C\&T não vai construir sua base política dando atenção a eles; na verdade, isso pode gerar oposição.

No entanto, se os ESCT como um campo acadêmico tem uma responsabilidade com o público, não apenas com a política, então é parte de nosso trabalho chamar a atenção para todas as consequências da política de C\&T, ainda que algumas delas possam causar desconforto político. Ned Woodhouse não é alguém que evite desconfortos, e tenho orgulho da honestidade com a qual nós levantamos essas questões, no artigo que vocês citaram. Eu também levantei-as em outros lugares desde então.

Entrevistador: Suas pesquisas recentes são focadas principalmente nas Tecnologias Emergentes e sua relação com desigualdades, especialmente em países menos desenvolvidos. Mas se alguém olhar para seus primeiros trabalhos, encontrará um conjunto diferente de objetos e questões. Qual é 
sua principal preocupação ao mudar das comunidades científicas para o fenômeno tecnológico? Isto está, de algum modo, relacionado à virada tecnológica nos ESCT, descrita por Steve Woolgar ${ }^{10}$, no começo dos anos 1990? Uma vez que você estudou os dois fenômenos, quais são as principais diferenças entre a pesquisa sobre a tecnologia e ciência? Qual foi o movimento teórico? Que pressupostos inspiraram esta mudança?

Susan: A mudança para mim foi estimulada pelo pensamento amplo sobre o contexto social da pesquisa, muito mais do que por algum desenvolvimento interno no campo. A ciência encontra a sociedade na tecnologia. As indústrias apoiam mais os empreendimentos tecnocientíficos do que o governo, nos EUA. Então, quanto mais eu me movia para minhas próprias reflexões, mais eu me afastava da visão de mundo da $N S F$, que obviamente é muito mais focada em ciência do que em tecnologia. Uma vez que eu comecei a olhar para as consequências distributivas das políticas de C\&T fui inevitavelmente atraída para como o conhecimento de pesquisa é ou não traduzido em coisas que mudam a vida cotidiana de todos, sejam ricos ou pobres. Esse foco me levou profundamente para a inovação e difusão tecnológica.

Entrevistador: Em seu seminário aqui na Unicamp, você argumentou que "as tecnologias emergentes são um locus estratégico de pesquisa para examinar interações de desigualdades entre países e desigualdades dentro dos países", notadamente porque essas tecnologias têm um impacto significativo no acesso ao mercado de trabalho e ao emprego - uma preocupação bem macroeconômica. Também em seu artigo "Water Supply and Sanitation as a Sectoral Innovation System"11 você volta a análise para as tecnologias emergentes capazes de melhorar as condições de vida das pessoas pobres em regiões e/ou países em desenvolvimento. Esta análise parece muito uma virada mais enfática em direção às tecnologias para a redução das desigualdades e garantia das condições de vida para as pessoas pobres. Isso significa que há uma nova agenda para os pesquisadores dos ESCT?

Susan: O tópico da dinâmica da distribuição certamente não recebeu muita atenção dos ESCT no passado. No entanto, é um assunto muito importante, que deveria receber mais atenção no futuro. Ele não precisa ser adotado por todo pesquisador dos ESCT. Mas mesmo quando lidamos com gênero, mesmo quando lidamos com raça e etnicidade, nós estamos frequentemente pressupondo condições de vida de classe média.

$\mathrm{Na}$ realidade, existe muito pouco publicado na Social Studies of Science (SSS) e na Science, Technology and Human Values (STHV) sobre os países em desenvolvimento, e o que é publicado não aborda as realidades fundamentais, então os estudantes não sabem o que fazer se eles querem estudar este tema (mas esta é uma questão completamente diferente). Os pressupostos das condições do Norte - do Norte global - em grande parte da literatura ESCT, ao menos em inglês, é algo do qual nós não podemos nos livrar facilmente. E existe muito trabalho, existe uma enorme quantidade de trabalho por aí, ainda para ser feito, apenas considerando a relação entre a variedade de comunidades e tecnologias que estão chegando até nós. Sim, eu penso que existe muito trabalho a ser feito e espero que coletivamente possamos inspirar alguns de nossos colegas a tomar essa tarefa para si.

Entrevistador: Existem vários conceitos econômicos como setores econômicos, demanda, suprimento e oportunidade nestes dois artigos. Quais são as vantagens e desvantagens de empregar este tipo de conceito, ao invés de um repertório mais sociológico?

Susan: É por trabalhar com políticas públicas que eu adotei isso. Se você realmente quer ser ouvido quando está escrevendo ou falando para audiências das políticas públicas, você deve falar na linguagem na qual eles estão habituados. Se nós tivéssemos formulado isso inteiramente em termos que não são provenientes da economia, nós teríamos muitas pessoas com quem nós estávamos tentando conversar dizendo: "e quanto aos setores econômicos?". Nós temos que ser capazes de falar no seu referencial, no referencial através do qual eles pensam sobre o mundo.

Um exemplo disso surgiu, de fato, no projeto RESIST ${ }^{12}$ : um de nossos conselheiros disse "todo mundo está falando sobre Sistemas de Inovação, vocês precisam traduzir o que vocês aprenderam do RESIST em termos dos Sistemas de Inovação, ou os policymakers não saberão realmente sobre o que vocês estão falando". Nós não fizemos isso, na verdade, mas este é um exemplo. Esse é o vocabulário que é esperado, parte do desafio é falar sobre coisas novas através de alguns dos vocabulários antigos, para que os policymakers não fiquem para trás.

Entrevistador: Quando falamos de pesquisa, ou de pesquisa orientada para ação, para Tecnologias Sociais algo que sempre preocupa é o papel das pessoas nesses projetos. Elas estão apenas sendo observadas? Elas estão fazendo parte dos projetos? O que é esperado delas? O que 
elas podem fazer quando nesse tipo de situação? Normalmente, nós vemos a Universidade indo até as comunidades, tentando ensinar através de programas de extensão. Normalmente, a Universidade está tentando ensinar a comunidade o que fazer. Existem poucos exemplos onde vemos que a Universidade aprende algo da comunidade, e quando você tem a preocupação em reduzir as desigualdades, você quer saber como se comportar como um ator que está no mesmo nível das pessoas que não possuem o mesmo tipo de expertise ou conhecimento.

Susan: Este é o tipo de quebra-cabeças no qual, se você realmente vai fazer alguma coisa nova, você deve usar todas as capacidades disponíveis para a humanidade e você precisa ter alguém com alguma expertise em interação para trazer o conhecimento que eles possuem. Mas então, como você cria uma situação de conhecimento igualitário, no qual todos os tipos de conhecimento são tratados da mesma maneira, e a comunidade acaba no controle dos meios de produção, de acordo com a visão da Tecnologia Social?

Inicialmente, eu estava pensando de modo mais amplo sobre onde se originam essas tecnologias com as quais convivemos e qual é o papel do público na relação com a maior parte das tecnologias ao seu redor. Se você olhar nessa sala, existe o gravador, os telefones celulares, os computadores, a cafeteira, e nenhum perito veio trabalhar com a comunidade para desenvolver qualquer uma delas. As companhias estão à solta, o grande guia da maior parte das tecnologias com as quais convivemos são companhias privadas tentando fazer dinheiro através da produção de novos produtos e processos que eles pensam alguém irá comprar.

O principal papel do público, de todos os públicos em relação à tecnologia, é realmente de consumidores. Alguns acadêmicos estão tentando captar as percepções do público, mesmo no desenvolvimento de tecnologias que estão dentro das firmas privadas. Isso é chamado de Avaliação Tecnológica Participativa ${ }^{13}$, que é apenas uma das muitas versões desse processo. Elas não são tão fortes como os processos moldando as tecnologias com as quais convivemos, como as firmas que estão olhando para os mercados. Eu suponho que, no final das contas, o número de diferentes papéis que todos nós, como membros do público, temos agora em relação às tecnologias são muito importantes e partes da nossa comunidade de Ciência, Tecnologia e Sociedade (CTS) estão tentando inventar outros papéis e demonstrá-los e mostrar qual o poder desses outros papéis; mas eles ainda são pequenos.

Entrevistador: Existe uma política ou existem ferramentas para se pensar ou mesmo promover esse tipo de ação?

Susan: A principal é chamada de Avaliação Tecnológica, particularmente Avaliação Tecnológica Participativa, e colhe as impressões de certa parte do público enquanto a tecnologia está sendo desenvolvida. Por exemplo, no caso da nanotecnologia, nós usamos um modelo existente, que seleciona cerca de doze ou quinze pessoas em seis diferentes cidades dos Estados Unidos, para que elas olhem as tecnologias e para que, então, aceitemos as impressões deles. As empresas irão fazer aquilo que iriam fazer originalmente em relação a isso, independentemente dos resultados da Avaliação Tecnológica Participativa, mas alguns assuntos podem emergir desta maneira e o sistema pode lidar com eles. Esta é uma questão muito complicada. Nós realmente temos escolha tecnológica, em um sentido amplo? Não serei eu quem vai responder isto.

Entrevistador: Muitas vezes nós percebemos que aqui no Brasil os acadêmicos tendem a emular referenciais da Europa e dos Estados Unidos. Especialmente nos ESCT, isso parece ser uma tendência forte, tentando adequar nossa realidade a esses referenciais. Nós não temos uma tradição teórica muito forte. Isso também acontece com as Políticas Públicas: de tempos em tempos nós apenas pegamos algo do Norte e tentamos empurrar isso para nossa realidade política. O que você acha que são as principais consequências disso e, na sua opinião, existe alguma maneira de atingir algum tipo de autonomia teórica e política?

Susan: Existe uma enorme imitação acontecendo na Política de Ciência, Tecnologia e Inovação e os pesquisadores do campo são obviamente responsáveis por isso. Eles frequentemente vêm de seus empregos em laboratórios e pesquisa científica, ou eles são engenheiros e, portanto, eles não têm nem mesmo um referencial para pensar sobre o que estão fazendo, eles conhecem as instituições onde estão e dizem: "OK, nós queremos ser mais fortes. Certo, vamos fazer como os Estados Unidos fazem".

Ainda mais comum, eu penso, neste ponto, é olhar para o modelo dos Tigres Asiáticos e dizer "Certo, nós vamos fazer como a Coréia do Sul fez, como Taiwan fez, porque eles eram países pobres e eles fizeram muito dinheiro através das tecnologias e então nós vamos seguir esse caminho também." Existe muita imitação desse tipo acontecendo! Eu tenho uma palestra que eu dou com certa frequência, que eu estou transformando em um artigo agora, sobre como essas mesmas políticas 
sobre alta tecnologia têm consequências muito diferentes em diferentes sistemas, dependendo dos níveis educacionais, da população, de mecanismos redistributivos e da esfera política.

Elas criarão muito mais desigualdade em países onde existe muita desigualdade, onde os níveis de educação são geralmente baixos e até mesmo onde existe muita desigualdade de educação, ao contrário de um contexto como a Finlândia. Sim, elas têm consequências muito diferentes em lugares diferentes. Elas não são bem-sucedidas em todos os lugares, no entanto elas ainda têm muito apelo para os policymakers. Como alguém poderia atingir autonomia teórica e política nesses assuntos? São os tomadores de decisão que realmente precisam disso.

Eu penso que nós, os acadêmicos do campo, temos um pouco de autonomia. Podemos refletir e prover esta crítica. Eu penso que o principal para o pessoal da política é que eles possuam exemplos de outras abordagens que funcionaram e a articulação do porquê, e diante de quais circunstâncias, elas serão mais apropriadas do que as coisas que eles estão emulando. Existem muitos exemplos por aí e como acadêmicos nós podemos trabalhar produzindo alguns deles e dizer: "Vejam! Funcionou quando nós usamos a abordagem participativa, ou quando uma organização realmente possuía uma agenda para trabalhar as questões da redução da pobreza através da tecnologia". Existe algum movimento, mas ainda há muita educação para ser feita. Por exemplo, no caso dos parques tecnológicos: eles existem pelo mundo inteiro. Como é possível que isso funcione da mesma maneira em todos os lugares do mundo onde se tentam implantá-los? Imagine: eles trazem pessoas da Europa e dos Estados Unidos, para treiná-los. Na realidade, nem nos Estados Unidos eles funcionam! $!^{14}$

Entrevistador: Como última questão, o que nós queremos é mais um comentário seu. Como você sabe, esta entrevista é voltada para estudantes e para acadêmicos dos ESCT e de Política de Ciência, Tecnologia e Inovação, principalmente para o público brasileiro, então nós gostaríamos que você falasse um pouco sobre como você enxerga o campo dos ESCT e de Política de Ciência, Tecnologia e Inovação hoje. Quais são as principais tendências? Quais são os tópicos mais importantes atualmente? O que é importante pesquisar, especialmente em países como o Brasil? $\mathrm{O}$ que o Brasil pode aprender desse tipo de pesquisa? Sobretudo, você poderia dar uma dica para os jovens estudantes que estão começando suas pesquisas neste campo, no Brasil?

Susan: Bem, essa é uma resposta pequena, nós apenas precisamos de algo como mais uma hora (risos). Eu estava na reunião da Society for Social Studies of Science em Washington, em 2009, foi a primeira na qual eu fui depois de um tempo, e o campo está enorme. Eu fiquei impressionada com o tamanho da reunião e com a diversidade de tópicos que estavam sendo discutidos por lá. Eu penso que o campo sempre fez um bom trabalho em identificar objetos de interesse na realidade geral e olhar para eles e perguntar todo tipo de perguntas interessantes sobre eles. Eu vi muitos objetos de pesquisa interessantes sendo discutidos.

Eu devo dizer que estou um pouco desapontada porque ainda existe um abismo entre as análises CTS e o mundo da Política, precisamente por conta desses diversos ângulos. Tudo o que se preocupa em ver a realidade a partir de muitas maneiras, torna difícil a comunicação com a Política. Do mesmo modo, eu estou desapontada com alguns dos pesquisadores mais voltados para a Política, que não estão levando a complexidade em conta, que são muito quantitativos, muito orientados para modelos, muito focados em bases de dados. Eu não acho que essa agenda irá necessariamente produzir muita compreensão sobre a realidade também. Eu creio que a diversidade do campo e o pluralismo do campo são sua real força.

Em termos dos jovens pesquisadores no Brasil, em particular, eu diria: reconheçam os pontos fortes aqui em seu país e na América Latina e se certifiquem em manter diversos grupos de referência. Não olhem apenas para o Norte, para as lideranças da Society for Social Studies of Science, para a sua maneira de pensar a ciência e a tecnologia, mas enraízem o que vocês fazem com sua própria realidade. Perguntem questões que são importantes de onde vocês vieram e onde vocês estão, e encontrem grupos de referências de pessoas que estão perguntando as mesmas questões. É por isso que eu estou saindo com o povo que faz Economia da Inovação, Economistas Evolucionários. Em seu âmago, eles têm os mesmos problemas que eu tenho e eu quero ir aonde as pessoas são apaixonadas pelas mesmas questões e querem realizar alguma coisa no mundo. Vão para onde vocês encontrem pessoas que são entusiastas das mesmas coisas que você é, porque é assim que vocês causarão algum impacto.

\section{Notas de fim}

1 Um delas foi o "Workshop sobre a Nova Geração de Política em Ciência, Tecnologia e Inovação", promovido pelo Centro de Gestão e Estudos Estratégicos (CGEE) no dia 22 de Março de 2010.

2 Ver: Barber, Bernard (1978). 
Henry Small é um cientista da informação, mais conhecido por seus trabalhos pioneiros no campo da bibliometria, por meio do desenvolvimento de análises de co-citações nos anos 1970. Ele entrou para a equipe do Institute for Scientific Information (ISI) em 1972, e desde então vêm sendo associado com essa instituição. Para saber mais: http://www.garfield.library.upenn.edu/essays/v15p293y1992-93.pdf

4 Para saber mais: http://isiwebofknowledge.com/

5 Derek John de Solla Price $(1922$ - 1983) foi físico, historiador da Ciência e cientista da informação e é creditado como o pai da cientometria.

Karen Knorr-Cetina.1982.

Latour, B.. Woolgar, S. 1997.

Cozzens, S.; Woodhouse, E.

Idem: 522

Woolgar, Steve. 1991.

Cozzens, S.; Catalan, P. 2009.

Para saber mais: www.resist-research.net/home.aspx

No original: Participatory Technology Assessment

Sobre esse tema, consultar Gomes, E. 1999 e Silva, R. 2009.

\section{Referências}

BARBER, Bernard. Science and the Social Order. Greenwood Press Reprint, Hardcover, 1978.

COZZENS, Susan E. Woodhouse, Edward. Science, Government, and the Politics of Knowledge. In: Jasanoff, Sheila et al. Handbook of Science and Technology Studies.

COZZENS, Susan; CATALÁN, Pablo. "Water Supply and Sanitation as a Global Innovation System", In: The International Water Association (IWA) Development Conference. Cidade do México, México, 2009.

GOMES, Erasmo Pólos, parques tecnológicos, incubadoras e desenvolvimento: fato ou artefato?. Redes, Buenos Aires, v. 17, n. 14, p. 177-216, 1999.

KNORR-CETINA, Karen. Scientific Communities or Transepistemic Arenas of Research? A Critique of Quasi-Economic Models of Science. Social Studies of Science. v. 12, n, 1, pp. 101-130, 1982.

LATOUR, Bruno. Woolgar, Steve. A Vida de Laboratório: a Produção dos Fatos Científicos (trad. Angela Ramalho Vianna). Rio de Janeiro: Relume Dumará, 1997.

SILVA, Rogério; DAGNINO, Renato. Pólos e Parques de Alta Tecnologia: uma alternativa?. Planejamento e Políticas Públicas, v. 33, p. 145-172, 2009.

WOOLGAR, Steve. The Turn to Technology in Social Studies of Science. Science, Technology and Human Values, London, Sage, Vol. 16, n. 1, p. 20-50, Winter, 1991. 